Research Article

\title{
Comparative Analysis of Dietary Intake Patterns of Rural and Urban Communities of Southern Punjab, Pakistan
}

\author{
Muhammad Luqman ${ }^{1, *}$, Roshan Hussain', Muhammad Yaseen, Muhammad Umer Mehmood', Ijaz \\ Asghar $^{2}$ and Usman Saleem ${ }^{1}$
}

${ }^{1}$ College of Agriculture, University of Sargodha, Pakistan; ${ }^{2}$ Department of English, University of Sargodha, Pakistan.

Abstract | This study draws the attention towards dietary intake patterns and their health impacts according to different communities in the southern Punjab, Pakistan. Southern Punjab has the most impoverished segments of society as compared to other parts of Punjab province. This transverse study was conducted in purposively selected three districts of Southern Punjab. Exactly sample size of 600 respondents (300 rural respondents and 300 urban respondents) was randomly selected through equal distribution technique and interviewed by using structured interview schedule. Data were analyzed using Statistical Package for Social Sciences and the following key results were obtained. Most of the respondents from the study were above the 30 years of age (mature), illiteracy was high in rural area and most of the respondents were dependent upon business and farming as their livelihood source. Among rural communities, food group of fats and sugars was much popular and urban community of study area was much inclined towards the food group of carbohydrates. Specifically, in breakfast both of the communities prefer proteins with fats and sugar commodities. In lunch rural community is much attracted towards carbohydrates and dairy products, while urban community prefers wheat bread with fruits and vegetables. Fruits, dry fruits and legumes are a best source of attaining maximum micro and macro nutrients. In comparison to this rural community of the study area perceived that vegetables and fruits are rich in macro and micro nutrients. Keeping in view the dietary pattern of rural as well as urban localities, best suitable timing must be kept in mind for specific food group to be included in the meal. Less nutritious food items must be used rarely as they contribute less to develop human health.

Received | October 30, 2020; Accepted | December 10, 2020; Published | February 06, 2021

*Correspondence | Muhammad Luqman, University of Sargodha, Pakistan; Email: muhammad.luqman@uos.edu.pk

Citation | Luqman, M., R. Hussain, M. Yaseen, M.U. Mehmood, I. Asghar and U. Saleem. 2021. Comparative analysis of dietary intake patterns of rural and urban communities of southern Punjab, Pakistan. Sarhad Journal of Agriculture, 37(1): 128-135.

DOI | http://dx.doi.org/10.17582/journal.sja/2021/37.1.128.135

Keywords | Diet, Food intake, Dietary patterns, Rural and urban communities, Food intake, Policy/ Pakistan

\section{Introduction}

$\mathrm{H}$ ealth is the stage of the human intended authority to adapt and manage people in the face of physical, mental or social problems. In general, regular interventions to prevent or cure health problems and promote good health of people are the choice of the intellectual life of a person and society. Numerous studies and reports from different organizations and contexts that sets the base of the relationship between health and various factors, including food components (Sarwar et al., 2014, 
2015). It's very much clear that there is prevalence of perception about studying the dietary intake patterns of South Asians and its impacts on their life-styles. Very few studies about the dietary intake patterns in Pakistan have been conducted (Safdar et al., 2013). Eating can be a basis for a healthy life. The diet consumed by the peoples, which is largely determined by the availability, use, and taste of the food. Balance in the diet indicates nutrients that health professionals recommend consuming enough (Sarwar et al., 2013). It is therefore important that lifestyle and nutrition education interventions be aimed at improving knowledge and behavior related to dietary practices that may involve older people in the community and may be at risk for malnutrition. Nutrition education programs have been shown not only to improve nutritional intake and health (Beebe et al., 2013; Francis and Taylor, 2009; Francis et al., 2014). The World Health Organization defines "youth" as 10-24 years and "adolescents" 10-19 years. Adolescence is the transition from a child into adulthood, characterized by physiological, psychological and social changes. Adolescence is a period of rapid growth in which $45 \%$ of skeletal growth occurs and 15-25\% of adult height is achieved, with $37 \%$ of bone mass accumulated (Reiss, 1989). Despite the variability in breakfast quality in people who eat breakfast, research shows that those who do not eat breakfast are constantly improving compared to their non-breakfast counterparts. Breakfast consumption has been proven to be important in weight regulation in adolescents. Consumption of unhealthy breakfast and even skipping the breakfast are the habits of adolescents in Pakistan (Paracha et al., 2016).

Frequently consumed foods are associated with increased drinking and reduced calcium intake. This reduction in calcium levels leads to a decrease in bone density during adolescence and may later lead to osteoporosis in life (Bowman et al., 2004). Increased consumption of fast food nowadays can be linked to a number of factors, including the increase in the number of females in the workforce, large families, and less time for planning and preparing meal. Increasing screen time is also seen as a factor in boosting fast food due to the number of ads promoting teenage restaurants. As a result of this, many college students develop the habit of snacking mindlessly throughout the day to temporarily curb their appetite. Students are also limited to purchasing snack items from vending machines and on-campus convenience stores and sometimes that is the only food source available to them. These overpriced food items are usually high in energy and low in nutritional value, and this may be a contributing factor to the unhealthy diets patterns commonly seen among college students (Ahmed, 2019). Creating good nutrition practices is critical to the success of the sport and care must be taken to avoid the long-term health consequences of this critical period (American Dietetic Association, 2009). Therefore, specific research was needed to analyze dietary intake and its impact on health among various communities in Rajanpur, D.G.Khan and Muzaffargarh district. In this context, research study was planned to analyze the dietary intake and its impact on health among various communities of District Rajanpur, D.G.Khan and Muzaffargarh. This study aimed to bridge the literature gap on dietary intake and its impact on health as this type of research study has never been conducted as previously in the Pakistan context.

\section{Materials and Methods}

The study was conducted in Southern Punjab, Pakistan. According to Punjab Economic Report (2020), this region beholds the most poverty rate than any other part of Punjab. This background set the base for purposefully selection of 03 poorest districts from southern Punjab (Rajanpur, D.G. Khan and Muzaffargarh). The population of the study comprised of all the people living in these three districts of Southern Punjab. It is much difficult to study the whole population in time, so randomly one tehsil was selected from each one of the districts (D.G. Khan from district D.G. Khan, Ali Pur from district Muzaffargarh and Rojhan from district Rajanpur).

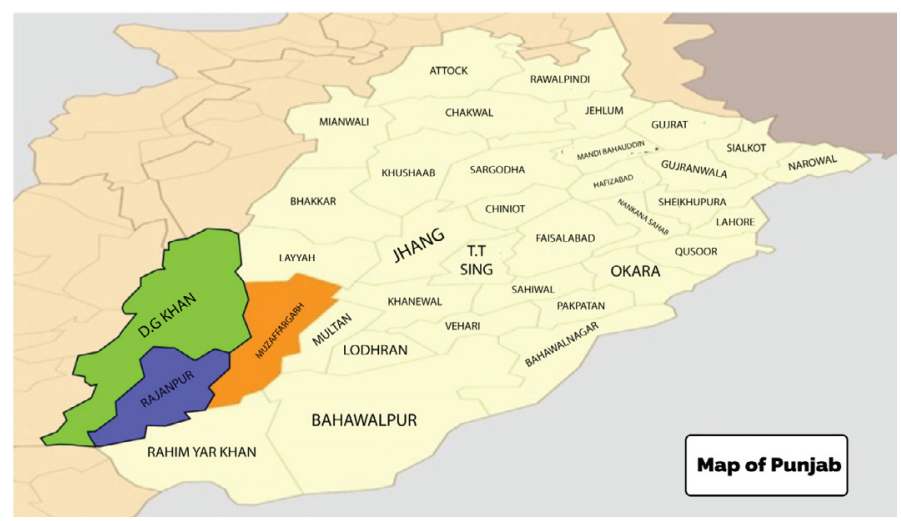

Figure 1: Map showing the study districts from Southern Punjab.

Data was collected from two types of respondents. One group was consisting of rural people whereas 
second group was consisting of urban people. From each group of every tehsil, 100 respondents from each were randomly selected keeping in view the financial and time constraints. Hence representative sample of 600 respondents was taken randomly from the selected area. Only male respondents were the participants of the study.

The tool used in the study was a detailed interview schedule for the data collection. The instrument was prepared by the team of expert at College of Agriculture, University of Sargodha. Nominal and interval scale of measurement were chosen to be part of the questionnaire. The questionnaire was translated into Urdu by the researcher to facilitate the purpose of the question to the respondents. Experts of agricultural extension, also reviewed the translated version of this tool. The researchers included mutually agreed comments on this tool. The researchers calculated the reliability of the instrument using Cronbach's alpha using the computer software "Statistical Package for Social Sciences" (SPSS).

The data thus collected was entered into Statistical Package for Social Sciences (SPSS) software. Mean, Standard derivation, and other basic statistical techniques were applied on different variables carried out in order to draw the results.

\section{Results and Discussion}

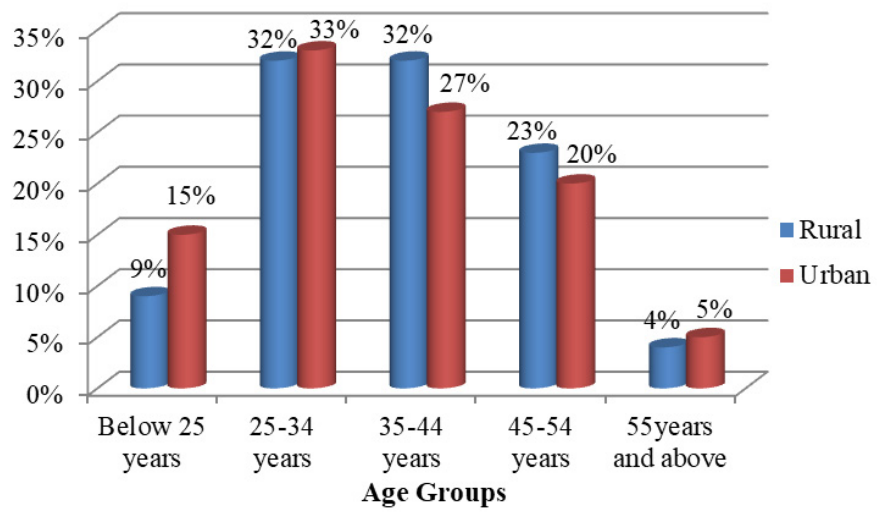

Figure 2: Data depicting age of the respondents.

In a study about the dietary intakes, age has a its special standing. The numerical results shown above depict that nearly one third (32\%) of the individuals selected from rural areas in the sample were young, while similar percentage of the people were lying under mature category, i.e. between 35 and 44 years. However, few of the rural inhabitants were also in adult age whereas some (4\%) of the respondents were also in old age. Furthermore, the sample taken from urban areas also depicted nearly the same pattern i.e. majority of the respondents were young. More than one fourth was quite mature enough that they had some knowledge about the topic under study. In addition to this, $4 \%$ and $5 \%$ of the respondents were of 55 years age and above from rural and urban settings consecutively.

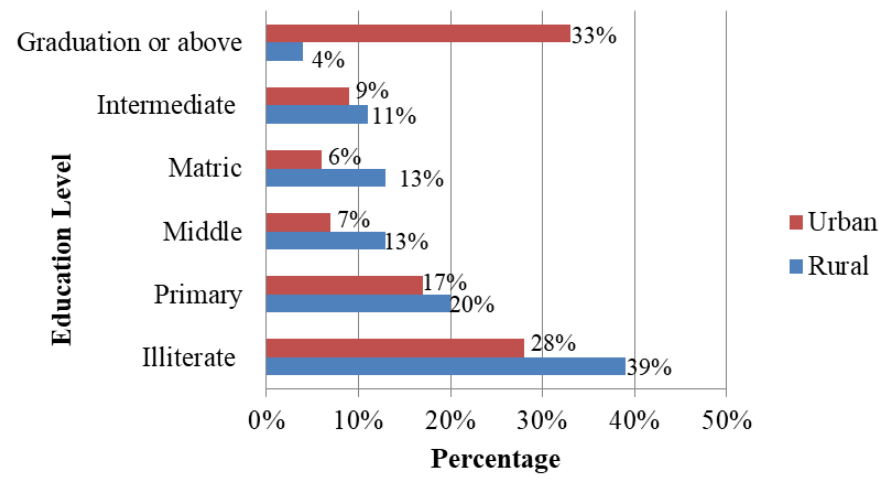

Figure 3: Data depicting education level of the respondents.

The Figure 3 shows that a large percentage i.e. 39\% of the sampled individuals were illiterate and illiteracy rate in urban setting was 28\%. This depicts the darker picture of educational activities going on in Pakistan as a whole. Though few in the sample were also graduated whereas some (11\%) of the sampled rural inhabitants had completed intermediate level of education. However, the urban sample depicts that comparatively small number of individuals were illiterate whereas quiet a large percentage $(33 \%)$ of the individuals if compared with rural individuals. Hence this concludes that urban communities could have an edge over the rural, because their literacy rate could make them able to productive decision about their diet pattern.

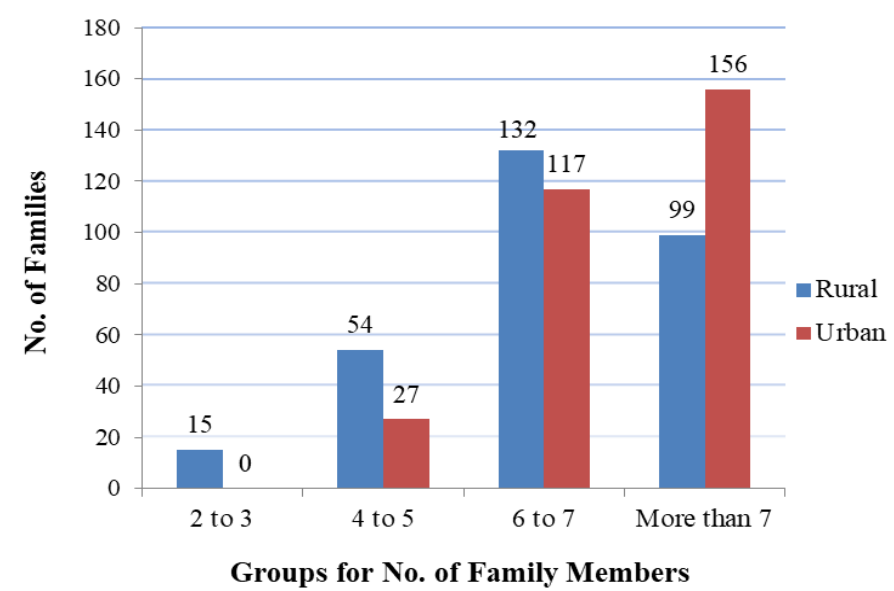

Figure 4: Data depicting family members of the respondents.

Figure 4 depicts large number (44\%) of individuals 
told that their family consists of 6 to 7 members. It might be due to the reason that they might be living in joint family system. One third of the individuals told that their family is consisting of more than 7 members. Few (5\%) of the individuals were of the view that have small family and it comprises of only 2 to 3 members. The urban sample depicts that more than half (39\%) of the individuals had their family members more than 7 while $39 \%$ of the individuals had their family members between 6 to 7 . Findings point towards the fact that in southern Punjab most of the families are of big size.

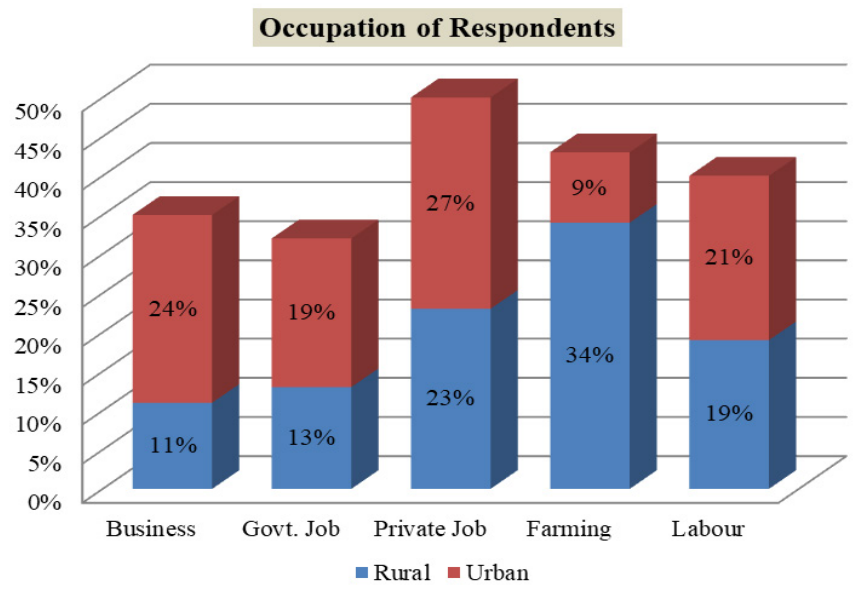

Figure 5: Data depicting occupation of the respondents.

Figure 5 showing the data related to occupation of the sampled individuals depicts that about one third (34\%) of the individuals from rural areas were doing only farming. However, some (11\%) were also doing some sort of business while nearly similar percentage of respondents $(13 \%)$ were government servants. In addition, urban majority (27\%) of the sampled people were doing some sort of private job while little less than this (24\%) were doing some sort of business. Little more than one fifth (21\%) were also laborers. This clarifies that majority of the respondents use to earn by working in the private sector and at farms from urban and rural areas consecutively.

Table 1 is all about the food groups which are most preferred by the residents living in totally different settings. Although all the food groups got the mean value of above 1.5 , anyhow medium level of intake from each food group is repeated in case of both communal settings. Explaining it more realistically, it's clear that food group of fats and sugars is most popular food group in the rural settings. While the food group of carbohydrates was the popular one in the urban stings and followed by the food group of milky and dairy products. This fact explains the facts that migration factor in the southern Punjab could not knock out their love for natural and more desi food. On the other hand in comparison to that, love for fats and sugars in the rural setting is more realistic because excessive amount of calories gained could easily burnt by some hours work in the fields.

Table 1: Tabulated data depicting mean and SD of the awareness level of the respondents regarding food groups.

\begin{tabular}{|c|c|c|c|c|c|}
\hline \multirow[t]{2}{*}{ Awareness level } & \multicolumn{3}{|l|}{ Rural } & \multicolumn{2}{|c|}{ Urban } \\
\hline & Mean & S.D. & Rank & Mean & S.D. Rank \\
\hline Proteins (Meat, Fish and eggs as well as vegetable protein, nuts, beans, peas, Lentils, soya) & 1.64 & 0.732 & 4 & 1.78 & .7333 \\
\hline $\begin{array}{l}\text { Fats and sugars (Butter, margarine, cooking oils, cream, salad, dressings, chocolate, crisps, } \\
\text { sugary soft drinks, sweets, jam, cakes, pudding, biscuits, pastries, fruits and vegetables) }\end{array}$ & 1.97 & 0.937 & 1 & 1.78 & .7463 \\
\hline Milk and dairy products (milk, yogurt, milkshakes, cheese, Lassi) & 1.84 & 0.707 & 3 & 1.90 & .7452 \\
\hline $\begin{array}{l}\text { Carbohydrates (pasta, rice, oats, potatoes, noodles, green bananas, sweet potato, millet } \\
\text { breads, cereals, barley, rye) }\end{array}$ & 1.85 & 0.857 & 2 & 1.94 & .6641 \\
\hline
\end{tabular}

Scale: 1: Low; 2: Medium; 3: High.

Table 2: Tabulated data depicting mean and SD of respondents eating babit in breakfast.

\begin{tabular}{|c|c|c|c|c|}
\hline \multirow[t]{2}{*}{ Eating habits } & \multicolumn{2}{|l|}{ Rural } & \multicolumn{2}{|c|}{ Urban } \\
\hline & Mean & S.D. & Mean & S.D. \\
\hline Proteins (Meat, Fish and eggs as well as vegetable protein, nuts, beans, peas, Lentils, soya) & 2.96 & 0.92 & 2.78 & 0.924 \\
\hline $\begin{array}{l}\text { Carbohydrates (pasta, rice, oats, potatoes, noodles, green bananas, sweet potato, millet breads, cereals, } \\
\text { barley, rye) }\end{array}$ & 3.05 & 1.06 & 2.47 & 0.98 \\
\hline Milk and dairy products (milk, yogurt, milkshakes, cheese, Lassi) & 3.22 & 1.024 & 2.24 & 0.96 \\
\hline $\begin{array}{l}\text { Fats and sugars (Butter, margarine, cooking oils, cream, salad, dressings, chocolate, crisps, sugary soft } \\
\text { drinks, sweets, jam, cakes, pudding, biscuits, pastries, fruits and vegetables) }\end{array}$ & 3.1 & 1.06 & 2.52 & 0.99 \\
\hline
\end{tabular}

Scale: Never: 1; Monthly: 2; Fortnightly: 3; Weekly: 4 and Daily: 5. 
More specifically talking about breakfast preferences Table 2 explains the love of both communities from the same food groups. Data shows that residents of rural areas in the southern Punjab do intends to like products from group of milk and dairy products and this likeness is followed by the obvious fats and sugars (mean value 3.1). While the trend was in between monthly and fortnightly basis is prevailing in urban areas of Southern Punjab for proteins added by fats and sugars in the breakfast. In comparison to the rural areas, mean for food group of milk and dairy products in breakfast is much less in urban areas. This proves the fact that in the early morning it is very rare that the residents of urban areas in Southern Punjab may have access to milk based products.

For the $2^{\text {nd }}$ time food of the day Table 3 explains the situation of the study area. In the rural areas of Southern Punjab, people use to prefer milk and dairy products, especially in the summer season like; Lassi (traditional drink) and milk shakes. In between the monthly and fortnightly basis people living in urban areas of Southern Punjab use to have proteins with the addition of milk and dairy products as their lunch. In the mid of the day each individual needs a refreshing meal and a little especially the workers of private job and working in the field out there. Its also clear that these two sources of income are most popular ones in the study area.

In the end of the day an individual should have a lighter meal to avoid his stomach from much of suffering. Table 4 explains the dinner preferences of both of the communities from study area against a Likert scale of 5. Residents of rural areas like to have fats and sugars in the night with most preference of vegetables as a major part. This intake is usually supported by a glass of milk. On the other hand, residents of the urban setting in Southern Punjab take Carbohydrates followed by fats and sugars as their night meal. This sets the base for making their bodies more vulnerable to diseases in comparison to the rural people.

Food is all about its nutritional value. Either nutritionally sufficient to meet the need of the consumer or not. On a serious note, the quantity of macro and micro nutrients values the nutritional standing of an eating item. According to the rural consumers of Southern Punjab believe that fruits and organic vegetables have most of the beneficent macro and micro nutrients (Table 5). In addition to this, data states that after these two they believe that dairy products with dry fruits are of much importance. In contrast to that urban people of study area were being agreed with cerals and legumes, vegetables and fruits on the basis of macro and micro nutrients. Here is the factor literacy rate, which is definitely contradicting the perceptions of both of communities. Factor of education is affecting the perceptions of both of the communities according to their available resources and local traditions.

By having a look at the mean and standard deviation values, highest mean value was recorded for safe and hygienic food may be taken for the purpose to avoid health problems (Table 6). From the rural respondents according to which it can help to improve human health on priority basis. However, highest mean was responded by urban people for an apple a day and use of green leafy vegetables collectively. Replace one sugary drink (soda, juice, etc.) each day with a tall glass of water as a measure to improve human health received second highest mean value y the rural individuals while safe and hygienic food may be taken for the purpose to avoid health problems received second highest mean value by urban respondents. Sufficient diet may be given to the children for their body growth as measure to improve human health received the least mean value from the urban sample while Eat fresh fruits, vegetables rather than a snack for a balanced diet were rated least by rural respondents.

Table 3: Tabulated data depicting mean and SD of the respondents eating habit in lunch.

\begin{tabular}{|c|c|c|c|c|}
\hline Eating Habits & Rural & & Urban & \\
\hline & Mean & S.D. & Mean & S.D. \\
\hline Proteins (Meat, Fish and eggs as well as vegetable protein, nuts, beans, peas, Lentils, soya) & 2.96 & 0.97 & 2.61 & 1.02 \\
\hline $\begin{array}{l}\text { Carbohydrates (pasta, rice, oats, potatoes, noodles, green bananas, sweet potato, millet } \\
\text { breads, cereals, barley, rye) }\end{array}$ & 3.21 & 1.03 & 2.50 & 1.05 \\
\hline Milk and dairy products (milk, yogurt, milkshakes, cheese, Lassi) & 3.23 & 1.03 & 2.51 & 1.08 \\
\hline Fats and sugars (Butter, margarine, cooking oils, cream, salad, dressings, choce & 3.16 & 1.0 & 2.46 & 1.01 \\
\hline
\end{tabular}

March 2021 | Volume 37 | Issue 1 | Page 132 
Scale: Never:1; Monthly:2; Fortnightly:3; Weekly: 4 and Daily: 5.

Table 4: Tabulated data depicting mean and SD of respondents eating habit in dinner.

Eating Habits

Proteins (Meat, Fish and eggs as well as vegetable protein, nuts, beans, peas, Lentils, soya)

Carbohydrates (pasta, rice, oats, potatoes, noodles, green bananas, sweet potato, millet breads, cereals, barley, rye)

Milk and dairy products (milk, yogurt, milkshakes, cheese, Lassi)

Fats and sugars (Butter, margarine, cooking oils, cream, salad, dressings, chocolate, crisps, sugary soft drinks, sweets, jam, cakes, pudding, biscuits, pastries, fruits and vegetables)

Scale: Never:1; Monthly:2; Fortnightly:3; Weekly:4 and Daily:5. $\begin{array}{llll}3.17 & 0.96 & 2.38 & 0.92\end{array}$

Rural Urban

Mean S.D. Mean S.D.

$\begin{array}{llll}2.94 & 0.99 & 2.53 & 0.95\end{array}$

$2.96 \quad 1.01 \quad 2.61 \quad 1.02$

$\begin{array}{llll}3.23 & 0.98 & 2.55 & 0.98\end{array}$

Table 5: Tabulated data depicting mean and SD of respondent's agreement level regarding best sources of micro and macro nutrients for health.

Micro and macro nutrient sources

$\begin{array}{ll}\text { Rural } & \text { Urban } \\ \text { Mean SD } & \text { Mean SD }\end{array}$

Dairy products (Butter milk, Cow milk, Buffalo milk, Yogurt, Curd, Cream, Goat milk and Ice-cream) $3.201 .022 .84 \quad 1.0$

Meat and Products(Eggs, Sheep meat, Goat meat, Buffalo meat, Chicken meat and Beef)

$\begin{array}{llll}2.87 & 1.05 & 2.75 & 1.14\end{array}$

Vegetables (Reddish, Onions, Tinda, Cucumber, Spinach, Carrots, Brinjal, Lady finger, Turnip and

$3.29 \quad 1.47 \quad 3.34 \quad 1.01$

Cauliflower)

Fruits (Mango, Lychee, Melon, Grapes, Lemon, Dates, Orange, Apple, Guava, Pomegranate, Peach

$\begin{array}{llll}3.34 & 1.05 & 3.13 & 1.10\end{array}$ and Banana)

Dry fruits (Walnuts, Peanuts, Raisins, Coconut, Almond, Dates and dried Pistachio)

$\begin{array}{llll}3.11 & 1.14 & 2.76 & 1.19\end{array}$

Fats and oils (Butter, Soya bean oil, Dalda, Ghee, Corn oil and Lard)

$\begin{array}{llll}3.11 & 1.18 & 2.51 & 0.94\end{array}$

Sugar, sweets and beverages (Barfi, Honey, Jalebi, Sugar, Gur and Carbonated beverages ) $\quad 3.07 \quad 1.09 \quad 2.58 \quad 1.02$

Cereal and legumes (Gram, Rice, Wheat, Millet, Maize, Pulses and Beans)

$\begin{array}{llll}3.09 & 1.09 & 3.35 & 0.88\end{array}$

Scale: 1: Strongly Disagreed; 2: Disagreed; 3: Neutral; 4: Agreed; 5: Strongly Agreed.

Table 6: Tabulated data depicting mean and SD of dietary related measures to improve human health.

\begin{tabular}{|c|c|c|c|c|c|c|}
\hline \multirow[t]{2}{*}{ Suggestions } & \multicolumn{3}{|l|}{ Rural } & \multicolumn{3}{|c|}{ Urban } \\
\hline & Mean & S.D. & Rank & Mean & S.D. & Rank \\
\hline Safe and hygienic food may be taken for the purpose to avoid health problems. & 3.41 & .922 & 1 & 3.80 & .816 & 2 \\
\hline Replace one sugary drink (soda, juice, etc.) each day with a tall glass of water & 3.27 & 1.033 & 2 & 3.62 & 1.013 & 4 \\
\hline $\begin{array}{l}\text { If you get hungry between meals, snack on a handful of almonds or cashews, a piece of } \\
\text { whole fruit, or carrot sticks rather than reaching for candy bars or potato chips }\end{array}$ & 3.26 & .928 & 3 & 3.32 & .886 & 6 \\
\hline An apple a day & 3.22 & .938 & 4 & 3.84 & 1.002 & 1 \\
\hline Use of green leafy vegetables & 3.21 & 1.008 & 5 & 3.84 & .873 & 1 \\
\hline Don't overcook or burn your meal & 3.18 & 1.019 & 6 & 3.29 & 1.018 & 7 \\
\hline Sufficient diet may be given to the children for body growth & 3.18 & 1.067 & 6 & 3.09 & .922 & 10 \\
\hline Drink some water before meals. & 3.11 & 1.004 & 7 & 3.27 & 1.062 & 8 \\
\hline Swap white bread, rice, crackers and pasta & 3.03 & .926 & 8 & 3.36 & .871 & 5 \\
\hline Read the nutrition labels on foods before you buy them. & 2.98 & 1.092 & 9 & 3.10 & .980 & 9 \\
\hline Eat fresh fruits, vegetables rather than a snack for a balanced diet & 2.92 & .971 & 10 & 3.64 & .798 & 3 \\
\hline
\end{tabular}

Scale: 1: Strongly Disagreed; 2: Disagreed; 3: Neutral; 4: Agreed; 5: Strongly Agreed.

\section{Conclusions and Recommendations}

It was concluded that from the study area one third
(32\%) of the individuals selected from rural areas in the sample was young, while similar percentage of the people was lying under mature category. Large 
percentages i.e. 39\% of the sampled individuals were illiterate. Half $(50 \%)$ of the rural respondents were moderately aware about proteins food group which include (Meat, Fish and eggs as well as vegetable protein, nuts, beans, peas, Lentils, soya) while little over two fifth (41\%) of the individuals from rural areas were moderately aware about carbohydrates food groups. Among dairy products buffalo milk was rated high source of micro and macro nutrients by the urban individuals whereas butter and milk were rated highest source of micro and macro nutrients by rural people. Rural people are neutral about the fact that fruits intake have any type of impact on human health whereas $38 \%$ of the urban respondents agreed with the same. However, $44 \%$ of the rural individuals were also neutral about the fact that vegetable intake had some type of impact on human health.

On the basis of the conclusions of the study, different recommendations were made which are as follow:

- Rural inhabitants must be made aware about best nutritious foods locally available so that they may prepare balanced diet for them at reasonable cost.

- Concept of balanced diet must be promoted especially among rural people as this term very much new to them and they have limited knowledge about balanced usage of food items in the meal.

- Keeping in view the dietary pattern of rural as well as urban localities, best suitable training programs about dietary intake pattern must be encouraged.

- An executive body of interdisciplinary coordination should be developed which would provide the scientific advice to the concerned policy maker about population as a whole and special groups.

- Less nutritious food items must be used rarely as they contribute less to develop human health.

\section{Acknowledgements}

This manuscript is the part of research project titled "Dietary Intake and Food Supply Chain Analysis for Sustainable Food Security in Marginalized Rural Communities of the Punjab" funded by Office of Research, Innovation and commercialization (ORIC), University of Sargodha, Sargodha. The authors highly acknowledged the financial support provided by University of Sargodha.

\section{Novelty Statement}

Rural communities are generally ignored by development agencies in their nutrient related development initiatives. Current research deals with comparative analysis of dietary intake patterns of rural and urban communities of marginalized regions of the Punjab, Pakistan. The study provided policy guidelines for state departments to take initia-tives for healthy nutrition intake by especially by the rural communities to ensure sustainable food security in the region

\section{Author's Contribution}

Muhammad Luqman: Conceived the major idea of research as principal author.

Roshan Hussain: Reviewed the literature, prepared research instrument and collected data.

Muhammad Yaseen: Prepared initial draft of manuscript.

Muhammad Umer Mehmood: Field data collection and analysis

Ijaz Asghar: English editing of manuscript

Usman Saleem: Helped in data collection and data analysis.

\section{Conflict of interest}

The authors have declared no conflict of interest.

\section{References}

Ahmed, F., 2019. Understanding food insecurity experiences, dietary perceptions and practices in the households facing hunger and malnutrition in Rajanpur District, Punjab Pakistan. Pak. Persp. 24(2): 115-133.

American Dietetic Association.2009.Documentary on, is soy healthy for breast cancer survivors? Retrieved from: https://nutritionfacts.org/ video/is-soy-healthy-for-breast-cancersurvivors/

Beebe, N., S. Magnanti, L. Katkowski, M. Benson, F. Xu, M. J. Delmonico and I. E. Lofgren. 2013. Effects of the addition of T'ai Chi to a dietary weight loss program on lipoprotein atherogenicity in obese older women. J. Altern. Complement. Med., 19(9): 759-766. https:// doi.org/10.1089/acm.2012.0531

Bowman, S.A., S.L. Gortmaker, C.B. Ebbeling, M.A. Pereira and D.S. Ludwig. 2004. Effects 
of fast-food consumption on energy intake and diet quality among children in a national household survey. Pediatrics, 113(1): 112-118. https://doi.org/10.1542/peds.113.1.112

Francis, S.L. and M.L. Taylor. 2009. A social marketing theory based diet-education program for women ages 54 to 83 years improved dietary status. J. Am. Diet. Assoc., 109(12): 2052-2056. https://doi.org/10.1016/j.jada.2009.09.002

Francis, S.L., L. MacNab and M. Shelley. 2014. A theory-based newsletter nutrition education program reduces nutritional risk and improves dietary intake for congregate meal participants. J. Nutr. Gerontol. Geriatr., 33(2): 91-107. https://doi.org/10.1080/21551197.2014.90633 6

Paracha, P.I., S. Bakht, S.I. Paracha, F. Vriesekoop, I. Alam, Z. Din and N. Ullah. 2016. Nutritional status, dietary practices and physical activities of adolescents in public and private schools of Karachi, Pakistan. Obes. Res. Open J., 3(2): 3039. https://doi.org/10.17140/OROJ-3-125

Punjab Economic Report. 2020. Poverty Profiling in Punjab. Retrieved from; https://peri. punjab.gov.pk/system/files/Chapter\%202\%20
Poverty\%20Profilling\%20in\%20Punjab_0.pdf

Reiss, D., 1989. The practicing and representing family. Relationship disturbances in early childhood. pp. 191-220.

Safdar, N.F., E. Bertone-Johnson, L. Cordeiro, T.H. Jafar and N.L. Cohen. 2013. Dietary patterns of Pakistani adults and their associations with sociodemographic, anthropometric and lifestyle factors. J. Nutr. Sci., pp. 2. https://doi. org/10.1017/jns.2013.37

Sarwar, M.F., M.H. Sarwar and M. Sarwar. 2015. Understanding some of the best practices for discipline of health education to the public on the sphere. Int. J. Innov. Res. Educ. Sci., 2(1): 1-4.

Sarwar, M.F., M.H. Sarwar, M. Sarwar, N.A. Qadri and S. Moghal. 2013. The role of oilseeds nutrition in human health: A critical review. J. Cereals Oilseeds, 4(8): 97-110. https://doi. org/10.5897/JCO12.024

Sarwar, M.H., M.F. Sarwar and M. Sarwar. 2014. Understanding the significance of medical education for health care of community around the globe. Int. J. Innov. Res. Educ. Sci., 1(2): 149-152. 